\title{
MIDLIFE FACTORS THAT INFLUENCE THE AGING PROCESS: AN INDIAN PERSPECTIVE
}

\author{
S. Puri' ${ }^{1}$, M. Shaheen ${ }^{2}$, D.H. Pai Panandiker ${ }^{3}$, R. Sinha ${ }^{4}$
}

\begin{abstract}
Increasing number of oldest old worldwide has made human longevity a major area of scientific research. It is a wellestablished fact that the health of an individual and the population in general are the result of interactions between genetics and a number of environmental factors; nutrition and physical activity being of major importance. The Asian Indian phenotype predisposes Indians to NCDs, more so at an earlier age. Indian diets are in a state of transition with increasing amounts of refined carbohydrates and fats being consumed. Physical activity levels are markedly low. Concomitantly, a sharp rise in the prevalence of non-communicable diseases (NCDs) like diabetes, hypertension, cardiovascular diseases and cancers has been observed. Although some of the physiological changes experienced by older adults occur primarily as a result of the biological process of aging, lifestyle factors - such as diet and physical activity - are important modulators of the risk factors associated with chronic disease and even age related decline.
\end{abstract}

Keywords: Elderly, aging, midlife factors, NCDs.

\section{Introduction}

The physiological aging process starts once one reaches adulthood and continues throughout the middle age. While every individual ages at a different rate, the exposure to various environmental factors during this period can contribute not only to accelerating the aging process but may also influence the onset of chronic degenerative diseases which when superimposed on the aging process lead to further deterioration in the quality of life of the elderly. India is currently undergoing a rapid transition in its demographics as well as socioeconomic milieu. With better access to nutrition and health care and an increase in life expectancy to over 65 years, more Indians are living to an older age, often with chronic ailments. All those diseases which were characteristic of westernized societies in the past are now emerging as major health problems in developing and middle-income countries like India.

It is well established that at any Body Mass Index (BMI) and age, Asian Indians have higher body fat, visceral fat and waist circumference; lower skeletal muscle mass; thinner hips; short legs; profoundly higher rates of insulin resistance, metabolic syndrome, diabetes, dyslipidemia, hypoadiponectinemia, and increased

1. Associate Professor; 2. Research Fellow, Department of Food \& Nutrition, Institute of Home Economics, University of Delhi; 3. Chairman, ILSI-India; 4. Executive Director, ILSI-India

Corresponding Author: Seema Puri, Department of Food \& Nutrition, Institute of Home Economics, University of Delhi, dr.seemapuri@gmail.com cardiovascular risk than Europeans (1) which correlates with insulin resistance and adiponectin levels (2). These unique clinical and biochemical characteristics among Asian Indians in particular and South Asians in general are collectively referred to as the "Asian Indian Phenotype" or thin-fat phenotype. Hence, not only is the prevalence of NCDs greater among Indians but also the onset is at a much younger age. Moreover, the relationship of poor foetal growth with the development of NCDs in early adulthood is well known. There is evidence that low birth weight as well as "catchup growth" are associated with an increased risk of hypertension, insulin resistance, Type 2 Diabetes Mellitus, and Coronary Heart Disease (CHD) in adults $(3,4)$.

\section{Nutrition transition}

India is presently undergoing a nutrition transition in three stages. In stage 1, consumers moved away from traditional staple items to food products more prevalent in "westernized" diets. In stage 2, the influences of globalization were much more marked and the consumers have access to a variety of convenience foods often high in salt, fat, sugar, preservatives etc. In stage 3 , some people (especially those belonging to the high socioeconomic stratum) tend to realize adverse eating habits and try to adapt a healthy lifestyle. Most Indians are currently in the second stage of nutrition transition (5). This transition over the past 30 years (1973-2004), has resulted in a $7 \%$ decrease in energy derived from carbohydrates and a $6 \%$ increase in energy derived from 
fats. A decreasing intake of coarse cereals, pulses, fruits and vegetables, an increasing intake of meat products and salt, coupled with declining levels of physical activity due to rapid urbanization have resulted in escalating levels of obesity, atherogenic dyslipidemia, subclinical inflammation, metabolic syndrome, type 2 diabetes mellitus, and coronary heart disease in Indians (5).

\section{Dietary factors that influence aging in India}

\section{High carbohydrate consumption}

Energy intake from carbohydrates (particularly cereals) is higher in Asian Indians as compared to other ethnic groups (6). Cereals are the staple diet in India, and carbohydrate consumption constitutes the bulk of the total calorie intake. The decreasing consumption of cereals in the past two decades (7) may indicate a shift towards (more) energy-dense "fast" foods (highly processed, deep-fried, unhealthy foods, devoid of adequate nutrients) as a source of energy in the diets but it still contributes approximately $73 \%$ of the energy intake in rural areas and 68\% in urban areas. It is known that a high intake of carbohydrate ( $>55 \%$ of energy), even with a low fat intake, may lead to high serum triglyceride levels, hyperinsulinemia, and low levels of high density lipoprotein-cholesterol (HDL-C) (8). In addition, recent studies indicate that several dietary carbohydrates directly influence lifespan in various organisms through diverse signaling pathways $(9,10)$. It is seen that glucose consumption decreases the activity of AMP-activated protein kinase (AMPK), an energy sensor that regulates an organism's lifespan.

\section{High dietary fats}

Indian diets are primarily vegetarian, and plant foods being low in "invisible" fat content, do not contribute significantly to total fat intake. The "visible fats" are derived from animal sources such as ghee (clarified butter having a high content of saturated fat), butter, and vegetable oils (11). ICMR has recommended a total fat intake between $20 \mathrm{en} \%$ and $30 \mathrm{en} \%$ for Indian adults (12). Importantly, total fat intake has increased over the last three decades (1973-2005) in both rural (24- $35.5 \mathrm{~g} /$ day) and urban (36-47.5 g/day) populations in India (7, 13-15) due to an increase in the supply of fats and oils as well as an increase in the availability and consumption of energydense, high-fat diets (5). A recent report by NIN (2011) has shown the average intake of fats and oils among adult men to be $20 \mathrm{~g} /$ day and among adult women $17 \mathrm{~g} /$ day (16). A high-fat diet (HFD) is generally associated with increased mortality and increased incidence of many metabolic diseases, including type 2 diabetes and cardiovascular problems (17). It is seen that dietary lipids may affect mammalian health and longevity by altering the compositions of body fat and cellular membranes (18).

\section{Saturated fatty acids}

In the Indian diets, saturated fatty acids (SFAs) are mostly derived from butter and ghee in north, middle, and west India, and coconut oil in south India. The SFA intake is increasing in the middle SES. Indian foods such as parantha (Indian bread prepared on a griddle using fat), bhatura (Indian bread prepared by deep frying), samosa (snack prepared by stuffing potato in refined wheat flour dough cones and deep frying), and suji halwa (dessert prepared using refined wheat flour [semolina] and fried in oil) are prime sources of SFAs in Indian diets, particularly when ghee or vanaspati (obtained from partially hydrogenated vegetable oil), are used in their preparation (19). Coconut fat accounts for $80 \%$ of the fat intake among Indians residing in south India. Kerala has not only the highest level of blood cholesterol, but also the highest rate of CHD in India (20).

\section{Unsaturated fatty acids}

Diets enriched in natural unsaturated fatty acids lower blood pressure, improve insulin sensitivity, and reduce the risks of cardiovascular and metabolic diseases (21).

\section{Polyunsaturated fatty acids}

Studies indicate that polyunsaturated fatty acids (PUFAs) prevent aging-associated diseases and promote longevity. For example, arachidonic acids, which are omega ( $\Omega$ )-6 PUFAs, induce apoptosis of cancer cells (22). Saturated fatty acids and monounsaturated fatty acids are generally more resistant to oxidative damage than that of PUFAs with multiple double bonds (18). Thus, opposite from their potential role as dietary lipids, low levels of PUFAs in the membranes may be beneficial for longevity and health. Intake of n-3 PUFAs and long chain n-3 PUFAs is low in some South Asian populations, particularly among vegetarians (11). However, longitudinal cohort studies are needed in Indians to assess whether the ratio of $n-6: n-3$ or their absolute amounts play a role for the prevention and management of atherosclerosis (5).

\section{Monounsaturated fatty acids}

The MUFAs are present in the following oils: mustard, palm, olive, groundnut, rice bran, and soybean (all available in India), and some seeds (coriander, groundnut, sesame, and mustard) (23). Diets deficient in Monounsaturated fatty acid (MUFA) are reported to have detrimental effects on diastolic blood pressure (24) and lipid metabolism (25), particularly when the total fat intake is above the median ( $>37 \%$ of energy) (23). 
Data show that Indians belonging to low SES consume low amounts of MUFAs: males $4.7 \%$ and females 5.7\% (26). Rastogi et al (2004) compared persons consuming sunflower oil with those using mustard oil (the traditional cooking oil used in India, containing 70\% MUFA, 10\% ALNA and $12 \%$ LA) for cooking and frying and found that the latter had a significant lower risk for CVD after adjustment for age, sex, and smoking (27); however, dietary intervention to study the effects of MUFA-rich diets has not been attempted with Indians and needs investigation (5).

\section{Trans-fatty acids}

A high intake of trans-fatty acids (TFAs) has been associated with dyslipidemia and an increased risk of T2DM and CHD (28). Dietary trans-fats (unsaturated fatty acids with trans-isomers) trigger inflammatory responses, which increase the risks of developing cardiovascular and metabolic diseases (29). Indian diets as well as commercially fried, processed, baked, ready-to eat foods, and foods made by street vendors in India derive TFAs from partially hydrogenated vegetable oil, vanaspati due to its convenience of handling, low cost, and long shelf life (5). A TFA intake (percent energy) of 1.13 and 1.11 amongst adolescent and young adults in north India, respectively, has been reported by Misra et al (19).

\section{Low protein intake}

Protein intake among Indians is influenced by the vegetarian status of the majority of Indians whose protein is derived, apart from milk, from a combination of cereals and pulses, such as pulses and rice, and pulse and whole wheat unleavened bread (5). The NIN report (2011) revealed that the average intake of protein was around $60 \mathrm{~g} /$ day among 18-60 year old rural and urban men in India, while the average intake of protein was approximately $50 \mathrm{~g} /$ day among 18-60 year old women in rural and urban India (16). The consumption pattern of meat and related products is linked to the SES of the family in India. As Indians are becoming more affluent, animal foods are increasingly being consumed, both among rural and urban areas. Interestingly, plant proteins contain considerably lower methionine than animal proteins (30), and this low methionine content may underlie the beneficial effects of dietary plant on longevity.

\section{Dietary fibre, fruits and vegetables}

The intake of coarse cereals and millets, such as whole wheat flour, pearl millet, barley, sorghum, and maize (corn), along with husked pulses, fruits and vegetables have been the most important contributors towards dietary fibre in Indian diets (5). A dose-dependent inverse association is seen between vegetable intake and CHD in the metropolitan Indian cities (27). Nationally representative surveys in India, however, indicate a very low per capita consumption of fruits and vegetables both among rural and urban adults (16). In a study in south India, a higher intake of fruits and vegetables explained $48 \%$ of the protective effect against cardiovascular risk factors (31).

\section{Indian spices and dietary salt}

Spices have been an integral part of the Indian diets since ancient times. Some Indian spices have been reported to possess antioxidant and antimicrobial properties. In a natural mutant model of obese mice, turmeric (haldi) has been demonstrated to reduce the oxidation of LDL-C, lipid levels, blood glucose, and renal lesions (32); however, these beneficial effects of turmeric remain to be tested in human studies (5). Consumption of $25 \mathrm{~g}$ fenugreek seed powder in the daily diet has been shown to decrease blood glucose levels and has potential as an adjunctive therapy in the management of diabetes (33). Garlic, ginger, cloves and mustard may also have some antioxidant, antimicrobial, anti-thrombotic, antiinflammatory, and anti-cancer activities, as reported in (in vivo and in vitro) animal models in anecdotal studies (34).

Importantly, salt consumption has been found to be a significant predictor of hypertension in urban as well as in rural communities in north India (35). Population salt consumption, a strong determinant of high blood pressure and associated CVD, is very high across different regions with the average intake ranging between 8.5-9 grams/day $(6,36)$, with the intake being higher in urban compared to rural areas.

\section{Nuts and oilseeds}

Nuts and oilseeds are complex plant foods that are not only rich sources of unsaturated fat but also contain several non-fat constituents, such as protein, fibre, micronutrients (e.g. copper and magnesium), plant sterols, and phytochemicals (37). Long-term nut consumption has been associated with lower body weight and lower risk of obesity (38). The frequency and quantity of nut consumption has been documented to be higher in vegetarian than in non-vegetarian populations.

\section{Other Dietary Components}

Kumar et al (39) found that low vitamin B12 levels is linked with higher incidence of CAD in this population recruited from a tertiary care centre in New Delhi, India. Another observational study by Chahal, Raina and Kaur (40) showed low mean serum Vitamin B12 levels in both study groups of employees as well as students. There is widespread prevalence of varying degrees (50-90\%) of 
Vitamin D deficiency with low dietary calcium intake in Indian population according to various studies published earlier (41, 42). Tuohimaa (43) showed that Calcidiol (precursor of vitamin D), an active circulating hormone, is associated with an increased risk of aging-related chronic diseases more directly than calcitriol.

A study by Dherani et al (44) showed that the mean levels of serum vitamin $C$ in a north Indian population was $0.22 \mathrm{mg} / \mathrm{dl}$ and that of vitamin $\mathrm{E}$ ( $\alpha$ Tocopherol) is $0.23 \mathrm{mg} / \mathrm{dl}$. Such low concentrations are said to cause age-related diseases in long-term (45).

\section{Lifestyle factors that affect aging in India}

When centenarians and other long-lived individuals are studied, their longevity is often attributed to a healthy lifestyle. Three characteristic behaviours are routinely reported; these include exercising regularly, maintaining a social network, and maintaining a positive mental attitude (46).

\section{Physical Inactivity}

The impact of physical activity on primary aging processes is difficult to study in humans because cellular aging processes and disease mechanisms are highly intertwined (47). Rather, regular physical activity increases average life expectancy through its influence on chronic disease development (via reduction of secondary aging effects) (48).

Few studies have estimated the physical activity levels in Indian population so far. In a study by Ramachandran et al (49) on temporal changes associated with pattern of life style (1989-2003) there had been a decline in levels of physical activity. Moreover, fewer subjects were engaged in manual work (22.8\% in 2003 vs. 80\% in 1989). Rastogi et al (27) conducted a hospital-based case-control study and collected data from 350 cases of acute myocardial infarction and 700 controls matched on age, gender, and hospital in New Delhi and Bangalore. They observed a positive association between non-work sedentary activity and CHD risk; leisure-time exercise, as much as 35-40 minutes per day of brisk walking, was protective for CHD risk and sedentary lifestyles were positively associated with risk of CHD.

\section{Tobacco Use}

Tobacco use is also a leading risk factor for premature NCD associated death and disability and accounts for more than two-third of all new cases of NCDs. Tobacco smoke has been linked to cause premature skin aging (50). A recent national data from the Global Adult Tobacco Survey (51) indicated the overall prevalence of tobacco use to be $35 \%$, with increases noted in women compared to earlier surveys $(48 \%$ in men and $20 \%$ in women). Nearly two in five (38\%) adults in rural areas and one in four $(25 \%)$ adults in urban areas use tobacco in some form (52). Furthermore, over half of all adults are being exposed to second-hand smoke (51).

\section{Alcohol Consumption}

Alcohol consumption has both health and social consequences via intoxication and alcohol dependence. Pattern of alcohol consumption varies with geographical location in the country. In India, the estimated numbers of alcohol users in 2005 was 62.5 million, with around $17 \%$ of them, which translates into 10.6 million, being dependant users (53). According to NFHS-3, 35\% of ever married males report consumption of alcohol (54). Although moderate consumption of alcohol appears to be protective for heart attacks in western populations it appears to be either neutral or conferring higher risk among South Asians (55) possibly related to the binge drinking practices in India.

\section{Diseases that affect aging in India}

\section{Obesity}

The causes of profound accumulation of adipose tissue in an organism are primarily a combination of excessive caloric intake and a lack of physical activity (56). Studies in humans show that high total and abdominal adiposity are directly related to decreased telomere length, suggesting that obesity may accelerate the aging process (57).

The NFHS-3 (54) reported that among men, 8\% were overweight and $1 \%$ obese. The highest rates of overweight and obesity have been observed in the epidemiologically and nutritionally advanced states, which, incidentally, also have higher rates of NCD risk and disease burden (58). Misra et al (26) reported 25\% prevalence of obesity in the slums of Delhi.

\section{Dyslipidemia}

High serum lipid levels are major risk factors of coronary heart diseases that are influenced by lifestyle transition and urbanization. Limited information exists regarding the changing time-trends in lipid levels and the prevalence of dyslipidaemia in Indian subjects. ICMR study (59) reported $36.8 \%$ and $39.8 \%$ prevalence of hypercholesterolemia in the urban Delhi and rural Haryana respectively during 1991-94. Repeat crosssectional surveys among urban subjects in Jaipur showed $37 \%$ vs. $43 \%$ prevalence among men and women during 2001 and $33 \%$ vs. $29 \%$ during 2002-03 $(60,61)$. 


\section{Frailty and Sarcopenia}

There has been wide agreement amongst experts in the field that frailty is a distinct clinical entity, with a recent consensus statement defining frailty as (62): '....a medical syndrome with multiple causes and contributors that is characterised by diminished strength, endurance and reduced physiologic function that increases an individual's vulnerability for developing increased dependency and/or death.' Frailty has shown to predict the negative health outcomes that we associate with vulnerable older people such as disability, institutionalisation, hospitalisation, falls and death (63). Sarcopenia was first described by Rosenberg as the agerelated loss of skeletal muscle mass (64). Regardless of the definition used, prevalence increases with age but women do not always have a higher prevalence than men (65). The prevalence of sarcopenia was found to be $17.5 \%$ in a study by Tyrovolas et al (66). A multi-country study by WHO in community-dwelling older adults aged 50 years and above reported the incidence of frailty to be $55.5 \%$ (67).

\section{Non Communicable Diseases (NCDs)}

Non-communicable diseases (NCDs) contribute to around 5.87 million deaths that account for $60 \%$ of all deaths in India. India shares more than two-third of the total deaths due to NCDs in the South-East Asia Region (SEAR) of WHO. Major metabolic risk factors are obesity, raised blood pressure, raised blood glucose and raised blood total cholesterol levels. Besides being the leading cause of death globally, NCDs also cause impairments that, due to physical, environmental, social and/or attitudinal factors, can lead to disability. This reflects the accumulated effects of disease and injury during a person's life, as well as declining physical strength in older age (68).

\section{Conclusion}

Adverse perinatal events due to maternal nutritional deprivation may cause low-birth weight infants, which, coupled with early childhood "catch-up growth", leads to obesity in early childhood, thus predisposing to NCDs later in life. The nutrition transition in India has resulted in a decreasing intake of coarse cereals, pulses, fruits and vegetables, an increasing intake of meat products and salt, coupled with declining levels of physical activity due to rapid urbanization. This has resulted in escalating levels of obesity, atherogenic dyslipidemia, subclinical inflammation, metabolic syndrome, type 2 diabetes mellitus, and coronary heart disease in Indians. The Asian Indian phenotype makes Indians not only highly susceptible to NCDs but also at a much younger age. Most NCDs have shared risk factors (tobacco use, unhealthy diet, physical inactivity, alcohol use) and integrated interventions targeting these risks from middle age will not only help to prevent and control NCDs, but also ensure a good quality of life in advancing years. ndia.

Conflicts of Interest: None. This review was supported by a grant from ILSI

\section{References}

1. Deepa R, Sandeep S, Mohan V. Abdominal obesity, visceral fat, and type 2 diabetes- "Asian Indian Phenotype". In: Mohan V, Gundu Rao, eds. Type 2 diabetes in South Asians; Epidemiology, Risk factors and Prevention. New Delhi: Jaypee Medical Publishers 2006;138-152.

2. Chandalia M, Lin $P$, Seenivasan $T$, et al. Insulin resistance and body fat distribution in South Asian men compared to Caucasian men. PLoS ONE. 2007;2(8):e812

3. Godfrey KM, Barker DJ. Fetal nutrition and adult disease. Am J Clin Nutr 2000;71: 1344S-52S.

4. Bhargava SK, Sachdev HS, Fall CH et al. Relation of serial changes in childhood body-mass index to impaired glucose tolerance in young adulthood. N Engl J Med 2004;350: 865-75.

5. Misra A, Singhal N, Sivakumar B, Bhagat N, Jaiswal A, Khurana L. Nutrition transition in India: Secular trends in dietary intake and their relationship to diet-related non-communicable diseases. Journal of Diabetes 2011;3: 278-292.

6. Misra A, Vikram NK, Arya S, Pandey RM, Dhingra V, Chatterjee A, Dwivedi M, Sharma R, Luthra K, Guleria R, Talwar KK. High prevalence of insulin resistance in postpubertal Asian Indian children is associated with adverse truncal body fat patterning, abdominal adiposity and excess body fat. Int J Obes Relat Metab Disord 2004;28(10):1217-26.

7. National Sample Survey Organization, Ministry of Statistics and Program Implementation, Government of India. Report of the NSS 61st Round (July 2004- June 2005).

8. Misra A, Wasir JS, Vikram NK. Carbohydrate diets, postprandial hyperlipidaemia, abdominal obesity and Asian Indians: A recipe for atherogenic disaster. Indian J Med Res 2005;121: 5-8.

9. Schulz TJ, Zarse K, Voigt A, Urban N, Birringer M, Ristow M. Glucose restriction extends Caenorhabditis elegans life span by inducing mitochondrial respiration and increasing oxidative stress. Cell Metab. 2007;6, 280-293.

10. Lee SJ, Murphy CT, Kenyon C. Glucose shortens the life span of C. elegans by downregulating DAF-16/FOXO activity and aquaporin gene expression. Cell Metab. 2009;10, 379-391.

11. Misra A, Singhal N, Khurana L. Obesity, the metabolic syndrome, and type 2 diabetes in developing countries: Role of dietary fats and oils. J Am Coll Nutr 2010;29: 289S-301.

12. ICMR. Task force project on Collaborative study of coronary Heart Study, 2010.

13. National Sample Survey Organization, Ministry of Statistics and Program Implementation, Government of India, Report of the NSS 39th Round, 1983. Available from: http:/ / www.mospi.gov.in/nsso_test1. htm

14. National Sample Survey Organization, Ministry of Statistics and Program Implementation, Government of India. Report of the NSS 50th Round (July 1993 - June 1994). Available from: http:/ / www.mospi.gov.in/ nsso test1.htm

15. National Sample Survey Organization, Ministry of Statistics and Program Implementation, Government of India. Report of the NSS 55th Round (July 1999 - June 2000)

16. National Institute of Nutrition. A Report on Assessment of Consumption of Processed and Non-processed foods in India and Prevalence of Obesity Hypertension, Diabetes and Cardio metabolic risk factors. Report submitted to FSSAI, 2011.

17. Schrager MA, Metter EJ, Simonsick E, Ble A, Bandinelli S, Lauretani F, Ferrucci L. Sarcopenic obesity and inflammation in the InCHIANTI study. J. Appl. Physiol. 1985;102, 919-925.

18. Hulbert AJ (2010) Metabolism and longevity: is there a role for membrane fatty acids? Integr. Comp. Biol. 2010;50, 808 -817.

19. Misra A, Khurana L, Isharwal S, Bhardwaj S. South Asian diets and insulin resistance. Br J Nutr 2009;101: 465-73.

20. Mohan V, Deepa R, Rani SS, Premalatha G. Prevalence of coronary artery disease and its relationship to lipids in a selected population in South India: The Chennai Urban Population Study (CUPS No. 5). J Am Coll Cardiol. 2001;38: 682-7

21. Appel LJ, Sacks FM, Carey VJ, Obarzanek E, Swain JF, Miller ER III, Conlin PR, Erlinger TP, Rosner BA, Laranjo NM, Charleston I, McCarron P, Bishop LM. Effects of protein, monounsaturated fat, and carbohydrate intake on blood pressure and serum lipids: results of the OmniHeart randomized trial. JAMA 2005;294, 2455-2464.

22. Cao Y, Pearman AT, Zimmerman GA, McIntyre TM, Prescott SM Intracellular unesterified arachidonic acid signals apoptosis. Proc. Natl Acad. Sci. 2000;97, 11280-11285.

23. Gopalan C, Ramasastri BV, Balasubramanian SC. Nutritive Value of Indian 
Foods. National Institute of Nutrition, Indian Council of Medical Research, Hyderabad, 1989

24. Rasmussen BM, Vessby B, Uusitupa M et al. Effects of dietary saturated, monounsaturated, and n-3 fatty acids on blood pressure in healthy subjects. Am J Clin Nutr 2006;83: 221-6.

25. Rivellese AA, Maffettone A, Vessby B et al. Effects of dietary saturated, monounsaturated and n-3 fatty acids on fasting lipoproteins, LDL size and postprandial lipid metabolism in healthy subjects. Atherosclerosis 2003;167: 149-58.

26. Misra A, Pandey RM, Devi JR, Sharma R, Vikram NK, Khanna N. High prevalence of diabetes, obesity and dyslipidaemia in urban slum population in northern India. Int J Obes Relat Metab Disord 2001;25 (11):1722-9.

27. Rastogi T, Reddy KS, Vaz M et al. Diet and risk of ischemic heart disease in India. Am J Clin Nutr 2004;79: 582-92.

28. Salmeron J, Hu FB, Manson JE et al. Dietary fat intake and risk of type 2 diabetes in women. Am J Clin Nutr 2001;73: 1019-26.

29. Riserus U, Willett WC, Hu FB. Dietary fats and prevention of type 2 diabetes. Prog. Lipid Res. 2009;48, $44-51$.

30. McCarty MF, Barroso-Aranda J, Contreras F. The low-methionine content of vegan diets may make methionine restriction feasible as a life extension strategy. Med. Hypotheses 2009;72, 125-128.

31. Radhika G, Sudha V, Mohan Sathya R, Ganesan A, Mohan V. Association of fruit and vegetable intake with cardiovascular risk factors in urban south Indians. Br J Nutr 2008;99: 398-405.

32. Krishnaswamy K. Traditional Indian spices and their health significance. Asia Pac J Clin Nutr 2008;17(Suppl 1): 265-8.

33. Tapsell LC, Hemphill I, Cobiac L et al. Health benefits of herbs and spices: The past, the present, the future. Med J Aust 2006;185: S4-24

34. Khan A, Safdar M, Ali Khan MM, Khattak KN, Anderson RA. Cinnamon improves glucose and lipids of people with type 2 diabetes. Diabetes Care 2003;26: 3215-8

35. Goel NK, Kaur P. Dr. P.C. Sen Memorial Award, 1994: Role of various risk factors in the epidemiology of hypertension in a rural community of Varanasi district. Indian J Public Health 1996;40 (3): 71-6.

36. Mohan S, Reddy KS, Prabhakaran D. Chronic Non-communicable Diseases in India Reversing the Tide. Public Health Foundation of India, 2011

37. Rainey C, Nyquist L. Nuts - nutrition and health benefits of daily use. Nutr Today. 1997;32: 157-63

38. Sabate J, Ang Y. Nuts and health outcomes: New epidemiologic evidence. Am J Clin Nutr 2009;89: 1643S-8S.

39. Kumar KA, Lalitha A, Pavithra D, Padmavathi IJN, Ganeshan M, Rao KR, Venu L, Balakrishna N, Shanker NH, Reddy SU, Chandak GR, Sengupta S, Raghunath M. Maternal dietary folate and/or vitamin B12 restrictions alter body composition (adiposity) and lipid metabolism in Wistar rat offspring. J Nutr Biochem. 2012;24(1):25-31. doi: 10.1016/j.jnutbio.2012.01.004.

40. Chahal JS, Raina SK, Sharma KK and Kaur N. How common is Vitamin B12 deficiency - A report on deficiency among healthy adults from a medical college in rural area of North-West India. International Journal of Nutrition, Pharmacology, Neurological Diseases 2014; Vol 4; Issue 4

41. Marwaha RK, Tandon N, Garg MK, Kanwar R, Narang A, Sastry A, Saberwal $\mathrm{A}$, Bhadra $\mathrm{K}$ and Mithal A . Bone health in healthy Indian population aged 50 years and above, Osteoporos Int 2011;22(11); 2829-36

42. Harinarayan CV, Joshi SR. Vitamin D status in India-Its implications and remedial measures. J Assoc Physicians India 2009; 57:40- 48.

43. Tuohimaa P. Vitamin D and aging. The Journal of Steroid Biochemistry and Molecular Biology Volume 114, Issues 1-2, March 2009, Pages 78-84

44. Dherani M, Murthy GVS, Gupta SK, Young IS et al. Blood Levels of Vitamin C, Carotenoids and Retinol Are Inversely Associated with Cataract in a North Indian Population Invest Ophthalmol Vis Sci. 2008;49:3328 -3335

45. McCann JC, Ames BN. Vitamin K, an example of triage theory: is micronutrient inadequacy linked to diseases of aging? Am. J. Clin. Nutr. 2009;90, 889-907.

46. Spirduso WW, Francis KL, MacRae PG. Physical Dimensions of Aging.
Champaign (IL): Human Kinetics, 2005

47. Lakatta EG, Levy D. Arterial and cardiac aging: major share- holders in cardiovascular disease enterprises: Part I: Aging arteries: a "set up" for vascular disease. Circulation. 2003;107:139-46.

48. Holloszy J. The biology of aging. Mayo Clin Proc. 2000;75(Suppl):S3-8; discussion S8-9. 98.

49. Ramachandran A, Snehalatha C, Baskar ADS, Mary S, Sathish Kumar CK, Selvam S, Catherine S, Vijay V. Temporal changes in prevalence of diabetes and impaired glucose tolerance associated with lifestyle transition occurring in the rural population in India. Diabetologia, 2004;47:860- 86.

50. Morita A, Torii K, Maeda A and Yamaguchi Y. Journal of Investigative Dermatology Symposium Proceedings 2009; Volume 14, Issue 1, Pages 53-55

51. Global Adult Tobacco Survey, GATS India 2009-10. Ministry of Health and Family Welfare, New Delhi, India.

52. Jha P, Jacob B, Gajalakshmi V, Gupta PC, Dhingra N, Kumar R, Sinha DN, Dikshit RP, Parida DK, Kamadod R, Boreham J, Peto R; RGI- CGHR Investigators. A nationally representative case-control study of smoking and death in India. N Engl J Med 2008;358:1137-47.

53. Ray R. National survey on extent, pat- tern and trends of drug abuse in India. Ministry of Social Justice and Empowerment, New Delhi: Government of India and United Nations Office on Drugs and Crime,2004.

54. International Institute for Population Sciences (IIPS) and Macro International. National Family Health Survey (NFHS-3), 2005- 06: India: 2007; Volume I. Mumbai: IIPS.

55. Joshi P, Islam S, Pais P, Reddy S, Dorairaj P, Kazmi K, Pandey MR, Haque S, Mendis S, Rangarajan S, Yusuf S. Risk factors for early myocardial infarction in South Asians compared with individuals in other countries. JAMA 2007;297(3):286-94.

56. Lau DCW, Douketis JD, Morrison KM, Hramiak IM, Sharma AM, Ur E, and for members of the Obesity Canada Clinical Practice Guidelines Expert Panel. 2006 Canadian clinical practice guidelines on the management and prevention of obesity in adults and children [summary] CMAJ 2007;176(8): S1-S13. doi: 10.1503/cmaj.061409

57. Lee M, Martin H, Firpo MA, Demerath EW. Inverse Association Between Adiposity and Telomere Length: The Fels Longitudinal Study. Am J Hum Biol. 2011;23(1): 100-106

58. Mohan S, Reddy KS, Prabhakaran D. Chronic Non Communicable Diseases in India: Reversing the tide. Public Health Foundation of India, 2011

59. Indian Council of Medical Research. Community control of rheumatic fever and rheumatic heart disease. Report of ICMR task force study, 1994.

60. Gupta R, Prakash H, Gupta VP. Prevalence and determinants of coronary heart disease in a rural population of India. J Clin Epidemiol 1997;50(2):203-9.

61. Gupta R, Deedwania PC, Gupta A, Rastogi S, Panwar RB, Kothari K. Prevalence of metabolic syndrome in an Indian urban population. Int J Cardiol. 2004;97: 257-61

62. Morley JE, Vellas B, van Kan GA, et al. Frailty consensus: a call to action. J. Am. Med. Dir. Assoc. 2013;14, 392-7

63. Romero-Ortuno R \& Kenny RA. The frailty index in Europeans: association with age and mortality. Age Ageing 2012;41, 684-9

64. Rosenberg I. Epidemiologic and methodologic problems in determining nutritional status of older persons. (summary comments). Am. J. Clin. Nutr. $1989 ; 50,1231-3$

65. Morley JE. Sarcopenia: diagnosis and treatment. J. Nutr. Health Aging 2008;12, 452-506 6.

66. Tyrovolas S, Koyanagi A, Olaya B et al. Factors associated with skeletal muscle mass, sarcopenia, and sarcopenic obesity in older adults: a multicontinent study. Journal of Cachexia, Sarcopenia and Muscle 2016;7: 312-321

67. Arokiasamy P, Parasuraman S, Sekher TV and Lhungdom H. Study on global Aging and adult health (SAGE) Wave 1: India National Report, 2013.

68. World Health Organisation. World Report on Ageing and Health, 2015;p.29 